(6) OPEN ACCESS

'Department of Psychological Medicine and Neurology, Cardiff University School of Medicine, Cardiff, UK ${ }^{2} \mathrm{MRC}$ Centre in

Neuropsychiatric Genetics and Genomics, Cardiff University, Cardiff, UK

\section{Correspondence to}

Anita Thapar, Child and Adolescent Psychiatry Section, Department of Psychological Medicine and Neurology, Cardiff University, School of Medicine, Heath Park, Cardiff, CF14 4XN, UK;

thapar@cf.ac.uk

Accepted 20 July 2011 Published Online First 7 September 2011

\title{
What causes attention deficit hyperactivity disorder?
}

\author{
Anita Thapar, ${ }^{1,2}$ Miriam Cooper, ${ }^{1,2}$ Rachel Jefferies, ${ }^{1,2}$ Evangelia Stergiakouli ${ }^{1,2}$
}

\begin{abstract}
Attention deficit hyperactivity disorder (ADHD) affects around $1-3 \%$ of children. There is a high level of comorbidity with developmental and learning problems as well as with a variety of psychiatric disorders. ADHD is highly heritable, although there is no single causal risk factor and non-inherited factors also contribute to its aetiology. The genetic and environmental risk factors that have been implicated appear to be associated with a range of neurodevelopmental and neuropsychiatric outcomes, not just ADHD. The evidence to date suggests that both rare and multiple common genetic variants likely contribute to ADHD and modify its phenotype. ADHD or a similar phenotype also appears to be more common in extreme low birth weight and premature children and those exposed to exceptional early adversity. In this review, the authors consider recent developments in the understanding of risk factors that influence ADHD.
\end{abstract}

Hyperkinetic disorder was first described as a syndrome in 1902 by George Still, a UK paediatrician. The disorder is characterised by developmentally inappropriate hyperactivity, inattention and impulsiveness. These symptoms must be of early onset, present in more than one setting and associated with impairment in functioning (eg, peer relationships, educational achievement). The current diagnostic terms of hyperkinetic disorder, used in the International Classification of Diseases, 10th revision (ICD-10) and attention deficit hyperactivity disorder (ADHD), adopted by the Diagnostic and statistical manual of mental disorders, fourth edition (DSM-IV) are similar but not identical (see table 1 for DSM-IV criteria). ICD-10 has more strict criteria, with a threshold number of symptoms in each of the domains of inattention, hyperactivity and impulsivity needed for diagnosis. Prevalence rates overall in the UK vary from $1.4 \%$ for hyperkinetic disorder ${ }^{1}$ to $2.23 \%^{2}$ for ADHD. Those with intellectual disability (ID) and boys (3-4:1 male:female ratio) are more commonly affected.

Comorbidity is typical. ADHD commonly cooccurs with specific and global developmental and learning problems that include autistic spectrum disorders (ASDs), difficulties with speech and language, motor co-ordination and reading, as well as with a range of psychiatric disorders notably oppositional defiant disorder, conduct disorder and tic disorders. Anxiety, depression and more rarely bipolar affective disorder can also complicate the clinical presentation. Longitudinal studies show that ADHD symptoms and impairment often persist into adult life and are associated with increased risk of antisocial behaviour and substance misuse, ${ }^{3}$ poor educational attainment and workplace performance, unemployment, friendship difficulties and social problems. ${ }^{4}$

\section{CAUSES OF ADHD}

ADHD, like other common medical and psychiatric disorders (eg, asthma, schizophrenia), is influenced by multiple genes, non-inherited factors and their interplay. ${ }^{5}$ There is no single cause of ADHD and exposure to a risk factor does not necessarily result in disorder. This means that any given risk factor will only be observed in a proportion of cases and will also be found in those who are unaffected. Also, risk factors that contribute to the origins of ADHD might not necessarily be the same as those that influence its course and outcomes.

A further complexity is that genetic factors can exert indirect risk effects through interplay with environmental factors. Genes can alter sensitivity to environmental risks (gene-environment interaction), for example, environmental toxins or psychosocial adversity. ${ }^{6}$ Inherited factors can also influence the probability of exposure to certain environmental risks (gene-environment correlation; see later). This means that environmental and genetic risk effects cannot be considered as entirely distinct.

\section{GENETICS}

\section{Evidence of an inherited contribution to ADHD}

There is robust evidence from a wide range of study designs of a strong inherited contribution to ADHD. Family studies have consistently found higher rates of ADHD (twofold to eightfold increased risk) ${ }^{7}$ in parents and siblings of affected probands compared with relatives of unaffected controls. Twin studies have shown that monozygotic twin pairs have much higher concordance rates for ADHD than dizygotic twin pairs ${ }^{8}$ and adoption studies have also found increased rates of ADHD in the biological parents of ADHD adoptees compared with both the adoptive parents of the probands and with the parents of controls without ADHD (eg, Sprich et a ${ }^{9}$ ). Mean heritability estimates are around $79 \% .{ }^{10}$ However, heritability is not $100 \%$, suggesting non-inherited factors also contribute.

ADHD also appears to share an inherited liability with other neurodevelopmental and psychiatric problems, notably ASDs, developmental coordination problems,${ }^{10}$ reading ability, ${ }^{11} \mathrm{IO},{ }^{12}$ conduct and mood problems. ${ }^{13}{ }^{14}$ These findings suggest the same inherited and familial risks can result in the manifestation of different clinical phenotypes.

\section{Searching for ADHD susceptibility genes}

The high heritability of ADHD has fuelled efforts to identify susceptibility genes. As is the case for 
Table 1 DSM-IV criteria for attention deficit hyperactivity disorder Criteria can be met in either or both domains: for inattentive type, hyperactiveimpulsive type or combined type

Inattention

At least six of the following symptoms $\downarrow$

Fails to sustain attention in tasks or play activities

Often fails to follow through on instructions from others

Often avoids tasks that require sustained mental effort

Often easily distracted

Often loses things that are necessary for tasks or activities

Appears not to listen to what is being said to him/her

Fails to pay attention to details, or makes careless mistakes

Often forgetful in daily activities

Often has difficulty organising tasks

and activities

Additional criteria required: 0 nset before the age of 7 years, functional impairment, impairment present in more than one setting

DSM-IV, Diagnostic and statistical manual of mental disorders, fourth edition

other complex disorders, molecular genetic studies of ADHD have so far mainly been based on examining common DNA variation (the common disease-common variant hypothesis). This was originally investigated using candidate gene approaches, in which assumptions about the pathophysiology of the disorder are made, and more recently with 'hypothesisfree' genome wide association studies (GWAS), in which the frequencies of thousands of single nucleotide polymorphisms (SNPs) across the genome are compared between cases and controls. ${ }^{15}$ There is also emerging interest in the contribution of rare genetic variants to $\mathrm{ADHD}$.

\section{Examining specific genes of interest: candidate gene association studies}

There is a very large volume of literature on candidate genes reported to be associated with $\mathrm{ADHD}$, but only a few have consistently withstood replication (table 2) and meta-analyses.

The most robust evidence of association with ADHD has been shown for a dopamine D4 receptor gene (DRD4) variant. This receptor binds both dopamine and norepinephrine and there is a functional polymorphism (variable number tandem repeat-VNTR) in exon III of the gene that has been extensively studied. The seven-repeat allele of this polymorphism has been found to be associated with ADHD in different metaanalyses. ${ }^{16-18}$ The latest meta-analysis shows significant association of small effect size, ${ }^{19}$ although there is also evidence of substantial heterogeneity across studies.

Another dopamine receptor gene, DRD5, has also been consistently implicated. A microsatellite genetic marker located close $(18.5 \mathrm{~kb})$ but outside the gene region has also been found to be associated with ADHD in several meta-analyses, ${ }^{19}$ although again with evidence of moderate heterogeneity across studies.

The dopamine transporter gene (DAT1) was originally considered the most likely ADHD candidate gene because it is responsible for the reuptake of dopamine in the presynaptic cleft, ${ }^{20}$ inhibited by stimulants and also because the DAT1
Table 2 Candidate genes associated with ADHD selecting the most consistently replicated findings

\begin{tabular}{|c|c|c|c|c|}
\hline Gene & Polymorphism & OR & $\mathbf{P}$ & Consistency \\
\hline DRD4 & $\begin{array}{l}\text { 7-repeat allele of } \\
\text { VNTR in exon III }\end{array}$ & 1.27 & $<0.00001$ & $\begin{array}{l}\text { Replicated in four } \\
\text { meta-analyses/ } \\
\text { pooled analyses }\end{array}$ \\
\hline DRD5 & $\begin{array}{l}\text { 148-bp microsat- } \\
\text { ellite repeat }\end{array}$ & 1.22 & 0.000095 & $\begin{array}{l}\text { Replicated in four } \\
\text { meta-analyses/ } \\
\text { pooled analyses }\end{array}$ \\
\hline$D A T 1$ & $\begin{array}{l}\text { 480-bp VNTR in } \\
\text { 3' UTR }\end{array}$ & 1.1 & 0.002 & $\begin{array}{l}\text { Replicated in two } \\
\text { meta-analyses/ } \\
\text { pooled analyses, did } \\
\text { not replicate in four }\end{array}$ \\
\hline SNAP25 & T1065G & 1.15 & 0.03 & $\begin{array}{l}\text { Replicated in two } \\
\text { meta-analyses } \\
\text { but not same } \\
\text { polymorphism }\end{array}$ \\
\hline $\begin{array}{l}\text { COMT and } \\
\text { antisocial } \\
\text { behaviour in } \\
\text { ADHD }\end{array}$ & $\begin{array}{l}\text { Val158Met poly- } \\
\text { morphism }\end{array}$ & 2.82 & $<0.01$ & $\begin{array}{l}\text { Replicated in three } \\
\text { large independent } \\
\text { samples }\end{array}$ \\
\hline
\end{tabular}

Reported OR and $\mathrm{p}$ value are from Gizer et al meta-analysis ${ }^{19}$ apart from COMT, for which $\mathrm{OR}$ and $\mathrm{p}$ value are taken from Langley et al. ${ }^{26}$ ADHD, attention deficit hyperactivity disorder; COMT, catechol-0-methyltransferase; DAT1, dopamine transporter gene; DRD4, dopamine D4 receptor gene; DRD5, dopamine D5 receptor gene; SNAP25, synaptosomal-associated protein of 25 kD; UTR, untranslated region; VNTR, variable number tandem repeat.

knockout mouse exhibits hyperactivity and deficits in inhibitory behaviour. ${ }^{21}$ In the most recent meta-analysis, ${ }^{19}$ significant evidence of association was found with the 480-bp allele of the most commonly studied polymorphism (a VNTR in the 3' untranslated region (UTR) region of the gene) as well as with other polymorphisms in the same gene. The substantial heterogeneity reported could be the result of multiple polymorphisms in this gene increasing risk to ADHD or gene-environment interaction between the 3' UTR VNTR and prenatal factors, such as maternal alcohol consumption ${ }^{22}$ or maternal smoking during pregnancy, ${ }^{23}$ although these associations have not been widely replicated.

The gene encoding catechol $\bigcirc$ methyl transferase (COMT), which catalyses the degradation of dopamine, has also been studied extensively in ADHD. A functional polymorphism in the gene, which results in a valine-methionine transition and affects enzyme activity, has been the focus of many genetic studies. Neither meta-analysis ${ }^{19}$ nor pooled analysis ${ }^{17}$ has found any evidence of association with ADHD. There is however evidence that COMT could have a modifying effect on the ADHD phenotype rather than increase the risk of the disorder itself. The COMT val/val genotype (associated with greater enzyme activity) was found to be associated with antisocial behaviour in patients with $\mathrm{ADHD},{ }^{24}$ then replicated in two independent populations as well as shown in a pooled analysis. ${ }^{25}$ The association finding has been subsequently replicated in other studies and the link with antisocial behaviour appears to be mediated through impaired social understanding. ${ }^{26}$ This association is specific to antisocial behaviour in ADHD because it has not been observed with antisocial behaviour alone. ${ }^{25} 26$

\section{Searching across the genome for common genetic risk variants: GWAS}

Candidate gene association studies were relatively successful for ADHD compared with other neuropsychiatric/developmental disorders. However, GWAS findings for ADHD are still at an early stage, with no common gene variant having 
yet been identified. ${ }^{27}$ The same has been true for autism. The lack of genome-wide significant results may be because of the large sample sizes required. Because of the heavy multiple testing burden and the small effect sizes expected, tens of thousands of cases and controls are likely to be required, as has been shown in other complex disorders such as diabetes. ${ }^{28}$ None of the four published GWAS of ADHD has achieved genome-wide significant results. ${ }^{29-32}$ A meta-analysis of these studies that included 2064 parent-child trios, 896 cases and 2455 controls had a best $p$ value of $1.2 \times 10^{-6}$ and no SNP reached genome-wide significance $\left(p=5 \times 10^{-8}\right) \cdot{ }^{33}$

Although these results appear disappointing, it has to be remembered that ADHD GWAS studies are still in their infancy. Apart from sample sizes, which are clearly important, there is the issue of sample heterogeneity, which has also been highlighted by meta-analyses of candidate gene studies ${ }^{19}$ and can make collaboration and replication of significant results difficult. ${ }^{27}$ Another view is that disorders such as ADHD and autism may be better explained by the effect of rare genetic variants.

\section{The contribution of rare genetic variants: chromosomal anomalies, genetic syndromes and copy number variants}

A number of different chromosomal anomalies including abnormalities in the number of chromosomes (notably sex chromosome aneuploidies) and chromosomal structure as well as some single gene disorders have been found to be associated with higher rates of ADHD. Fragile X syndrome, tuberous sclerosis and several microdeletion syndromes including Smith Magenis and Velocardiofacial (VCFS; 22q11 microdeletion) syndromes are associated with ADHD (more commonly inattentive type). They are also associated with other neurodevelopmental and psychiatric disorders (eg, ASD, psychosis in VCFS). However routine screening in those without ID does not appear to be indicated. ${ }^{34} 35$

Copy number variants (CNVs) are a type of chromosomal structural variant. These DNA segments vary in size between people and can be either duplications, when there is a gain of DNA, or deletions, when there is a loss of DNA. They are part of the normal variation of the human genome. ${ }^{36}$ Large $(>500 \mathrm{~kb})$, rare $(<1 \%$ frequency) duplications and deletions have been implicated in the aetiology of neurodevelopmental disorders, such as autism, ${ }^{37}$ schizophrenia and ID. ${ }^{38}$ Studies that have examined rare CNVs of all sizes in ADHD have not found an increased rate of deletions or duplications in cases $^{39} 40$ but have found CNVs to be enriched for neurodevelopmental genes. In a UK study that focused on large, rare CNVs in ADHD (410 cases and 1156 controls), there was a significantly increased rate in cases compared with controls. ${ }^{41}$ This rate was especially high in those with ADHD and ID but was not restricted to this group. Restricting analysis to those without ID, this study also reported an overlap of CNVs found in ADHD with both autism and schizophrenia, further strengthening the notion of ADHD being a neurodevelopmental disorder. ${ }^{41}$

\section{ENVIRONMENTAL RISK FACTORS}

Inherited factors are not the only explanation of ADHD. Although there are a number of environmental risk factors that are associated with ADHD (table 3), identifying which of these are causal is challenging. This is because many observed associations might arise as a result of symptoms/disorder in the child or the parent (reverse causation eg, peer rejection, family adversity, ${ }^{42}$ low socioeconomic status ${ }^{43}$ or head injury), ${ }^{44}$

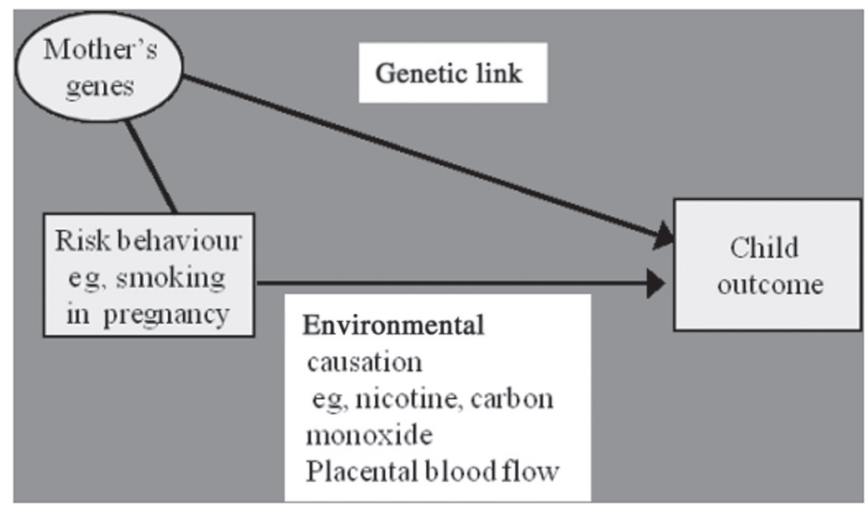

Figure 1 Mother's genes can influence ADHD as well as exposure to certain environmental factors.

Table 3 Environmental factors reported to be associated with ADHD

Maternally related prenatal risks Alcohol in pregnancy

Smoking in pregnancy

Drug use in pregnancy

Maternal stress in pregnancy

Maternal health in pregnancy (obesity)

Pregnancy and birth complications

Bleeding in pregnancy

Protracted/complicated delivery

Prematurity/low birth weight/intrauterine growth restriction

Low APGAR score

External agents

Infections

Exposure to lead and other toxins eg, PCB Nutritional factors

Psychosocial adversities

ADHD, attention deficit hyperactivity disorder; PCB, polychlorinated biphenyl.

or from unmeasured confounders that can include inherited factors (see figure 1). ${ }^{45}$ Interestingly, time trends studies have shown no increase in the population rate of ADHD over time, although identification has increased. ${ }^{46}$ Cross-national studies have not yet found consistent evidence of lower ADHD rates in certain countries. These findings contrast with data on childhood behavioural problems for which rates have risen in the last 50 years ${ }^{46}{ }^{47}$ and vary geographically. These results suggest that for ADHD there are more likely to be multiple environmental risks, each of small effect, with the overall burden of these risks remaining similar over time and between countries. Some of these risk effects might be modified by genetic influences (gene-environment interaction). Environmental risks can also alter gene function through tissue-specific epigenetic mechanisms. For example, animal studies have demonstrated how adverse early rearing has an impact on stress responses through such mechanisms and that these biological changes can be transmitted to subsequent generations. ${ }^{48}$

\section{Maternal smoking, alcohol, drug use and stress/anxiety in pregnancy}

Clinical and epidemiological associations show a consistent association $(\mathrm{OR}=2.39)^{49}$ and dose-response relationship between prenatal exposure to maternal cigarette smoking (maternal reports and urinary cotinine levels) and offspring ADHD. Although biologically plausible, because smoking is known to have an effect on physiological processes that may create risks relevant to the origins of ADHD, it is difficult to adequately control for familial and social confounds 
in observational designs. Recent studies suggest that the association with ADHD (but not with lower birth weight) may wholly or substantially represent familial and inherited confounds (gene-environment correlation). ${ }^{50} 51$

Alcohol is a known teratogen and prenatal exposure to heavy maternal drinking can cause foetal alcohol syndrome, the behavioural aspects of which include symptoms of inattention and hyperactivity. However, associations between less extreme alcohol use in pregnancy and offspring ADHD/ADHD symptoms are inconsistent. ${ }^{52} 53$ Findings are also inconsistent with regard to links with prenatal exposure to illicit drugs. ${ }^{52}$

Maternal stress in pregnancy has also been reported to be associated with offspring ADHD symptoms, although recent work suggests that for ADHD (but not antisocial behaviour or anxiety), this might also reflect inherited links between mother and child (gene-environment correlation) rather than being causal. ${ }^{54}$ In summary, with the exception of the extreme phenotype of foetal alcohol syndrome, the evidence that maternally related cigarette and substance use and stress in pregnancy play a major causal role in ADHD remains equivocal, although many of these factors are clearly detrimental for other offspring outcomes.

\section{Low birth weight and prematurity}

Most studies, including meta-analyses of premature and/ or low birth weight children, find evidence of an association with ADHD (relative risk of 2.64 for ADHD in premature children) ${ }^{55}$ and ADHD symptoms/attentional problems. ${ }^{56}$ The risk appears to be strongest for extreme prematurity and very low birth weight in relation to inattention symptoms and ADHD inattentive subtype. ${ }^{57} 58$ Some preliminary studies also suggest the likely importance of intrauterine growth restriction (small for gestational age). ${ }^{59} 60$ However it is not known whether low birth weight and/or prematurity and other associated pre/perinatal risks (see table 3 ) are risk markers of ADHD or whether they are causal. The findings at least suggest the need for heightened awareness of possible ADHD in very premature/low birth weight children.

\section{Toxins and diet}

Specific environmental exposures that seem to have relevance to the ADHD phenotype include organic pollutants (eg, pesticides, polychlorinated biphenyl (PCBs)) and lead. These may damage cognitive and neural systems known to be implicated in ADHD. 61

Associations between organophosphate pesticide exposure and $\mathrm{ADHD}$ have been investigated cross-sectionally, ${ }^{62}$ and prospectively (eg, Eskenazi et al, Marks et al, Rauh et al ${ }^{63-65}$ ) using assessments of prenatal and postnatal (childhood) urinary organophosphate metabolites and umbilical cord plasma levels of pesticides.

PCBs are a large group of toxic manufactured organic compounds that were previously mass produced. Both human and animal studies have examined the effect of PCB exposure on neurobehavioural outcomes similar to those affected in $\mathrm{ADHD}$, and these have found evidence of impairments in working memory, response inhibition and cognitive flexibility. ${ }^{66}$ A recent prospective study also found a positive association between low-level prenatal PCB exposure and ADHD-type behaviour in middle childhood, with a dose-response relationship. ${ }^{67}$ Both human and animal studies of lead exposure have shown similar impairments in executive functions and attention, with cognitive flexibility, vigilance and alertness being most reliably affected. ${ }^{66}$ There is also emerging evidence from several studies that lead could be implicated in ADHD even at low levels, but causality cannot be assumed from the evidence to date. Similarly, further work is needed to draw firm conclusions about how important pesticides and PCBs are as causes of ADHD.

Dietary constituents that have been studied in relation to ADHD symptoms include sugar, artificial food colourings, zinc, iron, magnesium and omega-3 fatty acids. There is no convincing evidence yet that diet plays a major causal role in ADHD. However, a separate issue relates to using dietary change to modify symptoms. Overall, the value of the studies looking at diet and ADHD are limited by small sized trials, subjective measures of outcome and varied protocols for intervention, and on this basis there has been inadequate evidence to suggest that dietary manipulation can ameliorate ADHD symptoms in children. ${ }^{68}$ However, a recent randomised controlled trial of a restricted elimination diet based on high or low IgG foods suggests a beneficial effect of a restricted elimination diet on ADHD and oppositional defiant disorder symptoms. ${ }^{69}$

\section{Psychosocial adversity}

Adverse social and family environments such as low parental education, social class, poverty, bullying/peer victimisation, negative parenting, maltreatment and family discord are associated with ADHD. However, the designs used so far have not been able to show that these are definite causes of ADHD. For example, longitudinal and treatment studies suggest that negative mother/son ${ }^{70}$ and peer relationships arise in response to child ADHD symptoms. This contrasts with findings for child antisocial behaviour/conduct disorder in which a variety of designs including treatment trials have consistently found that adverse social and family environments are causal. However, psychosocial factors might modify ADHD expression especially in those who are genetically susceptible, for example by influencing comorbidities such as conduct disorder, depression symptoms and level of impairment. This needs further investigation.

One exception is exposure to extreme early deprivation. A study of Romanian orphans adopted in the UK found a deprivation-specific inattentive and overactive pattern of behaviour. ${ }^{71}$ It remains to be examined whether a similar pattern of deficits arises in response to less extreme adversity.

\section{CONCLUSION}

In summary, there is strong evidence of an inherited contribution to ADHD, although non-inherited factors that likely include environmental risks and chance events (including de novo genetic changes) are also important. There is no single cause of ADHD and the risk factors that have been identified so far appear to be non-specific. That is, risks such as chromosomal microdeletions (eg, VCFS), large, rare CNVs, extreme low birth weight and prematurity appear to affect a range of different neurodevelopmental and psychiatric phenotypes. Genetic risks likely also include multiple common gene variants of small effect size that have yet to be identified, with the possible exception of a few dopaminergic genes. With the costs of DNA sequencing dropping, there is likely to be an increasing focus on identifying rare genetic variants, including structural variants such as CNVs and other rare mutations with larger risk effects.

Despite the rapid advances in genetics, there is still a need for further research into environmental risks. Although many 
factors are associated with $\mathrm{ADHD}$, different designs are needed to test which are causal. ${ }^{45}$ The strongest evidence relates to the links between ADHD/ADHD-like behaviours and relatively rare extreme adversities, specifically extreme prematurity, very low birth weight, foetal alcohol syndrome and a pattern of behaviours associated with institutional deprivation in the early years. Less is known about risk factors that modify ADHD outcomes. One exception is the association between COMT and antisocial behaviour in ADHD that is well replicated now and highlights that behavioural problems in those with ADHD may have different origins to behavioural problems in general.

Cumulatively, the available evidence goes some way towards highlighting groups who are at higher risk; specifically those who have a family history of ADHD and/or neurodevelopmental or learning problems, and those who have been exposed to the environmental adversities described earlier. However, none of these risks, including the genetic ones, provide tests or biomarkers of ADHD. It is hoped that, in the future, improved identification of ADHD risk factors and pathways will increase our understanding of the as yet unknown pathogenesis of ADHD and pave the way for improving diagnosis and treatment.

Acknowledgements Ongoing ADHD research supported by the Wellcome Trust. Competing interests None.

Provenance and peer review Commissioned; externally peer reviewed.

\section{REFERENCES}

1. Meltzer H. The mental health of children and adolescents in Great Britain. London: The Stationery Office 2000.

2. Ford T, Goodman R, Meltzer H. The British Child and Adolescent Mental Health Survey 1999: the prevalence of DSM-IV disorders. J Am Acad Child AdolesC Psychiatry 2003;42:1203-11.

3. Barkley RA, Fischer M, Smallish L, et al. Young adult follow-up of hyperactive children: antisocial activities and drug use. J Child Psychol Psychiatry 2004;45:195-211.

4. Barkley RA, Fischer M, Smallish L, et al. Young adult outcome of hyperactive children: adaptive functioning in major life activities. J Am Acad Child Adolesc Psychiatry 2006;45:192-202.

5. Thapar A, Langley K, Asherson P, et al. Gene-environment interplay in attentiondeficit hyperactivity disorder and the importance of a developmental perspective. Br J Psychiatry 2007;190:1-3.

6. Rutter M, Thapar A, Pickles A. Gene-environment interactions: biologically valid pathway or artifact? Arch Gen Psychiatry 2009;66:1287-9.

7. Biederman J. Attention-deficit/hyperactivity disorder: a selective overview. Biol Psychiatry 2005;57:1215-20.

8. Thapar A, Holmes J, Poulton K, et al. Genetic basis of attention deficit and hyperactivity. Br J Psychiatry 1999;174:105-11.

9. Sprich S, Biederman J, Crawford MH, et al. Adoptive and biological families of children and adolescents with ADHD. J Am Acad Child Adolesc Psychiatry 2000;39:1432-7.

10. Lichtenstein $\mathbf{P}$, Carlström E, Råstam $\mathrm{M}$, et al. The genetics of autism spectrum disorders and related neuropsychiatric disorders in childhood. Am J Psychiatry 2010;167:1357-63.

11. Paloyelis Y, Rijsdijk F, Wood AC, et al. The genetic association between ADHD symptoms and reading difficulties: the role of inattentiveness and IO. J Abnorm Child Psychol 2010;38:1083-95.

12. Kuntsi J, Eley TC, Taylor A, et al. Co-occurrence of ADHD and low IO has genetic origins. Am J Med Genet B Neuropsychiatr Genet 2004;124B:41-7.

13. Cole J, Ball HA, Martin NC, et al. Genetic overlap between measures of hyperactivity/inattention and mood in children and adolescents. J Am Acad Child Adolesc Psychiatry 2009;48:1094-101.

14. Thapar A, Harrington R, McGuffin P. Examining the comorbidity of ADHD-related behaviours and conduct problems using a twin study design. Br J Psychiatry 2001;179:224-9.

15. Thapar A, Stergiakouli E. Genetic influences on the development of childhood psychiatric disorders. Psychiatry 2008;7:277-81.

16. Faraone SV, Doyle AE, Mick E, et al. Meta-analysis of the association between the 7-repeat allele of the dopamine D(4) receptor gene and attention deficit hyperactivity disorder. Am J Psychiatry 2001;158:1052-7.

17. Faraone SV, Perlis RH, Doyle AE, et al. Molecular genetics of attention-deficit/ hyperactivity disorder. Biol Psychiatry 2005;57:1313-23.
18. Li D, Sham PC, Owen MJ, et al. Meta-analysis shows significant association between dopamine system genes and attention deficit hyperactivity disorder (ADHD). Hum Mol Genet 2006;15:2276-84.

19. Gizer IR, Ficks C, Waldman ID. Candidate gene studies of ADHD: a meta-analytic review. Hum Genet 2009;126:51-90.

20. DiMaio S, Grizenko N, Joober R. Dopamine genes and attention-deficit hyperactivity disorder: a review. J Psychiatry Neurosci 2003;28:27-38.

21. Gainetdinov RR. Dopamine transporter mutant mice in experimental neuropharmacology. Naunyn Schmiedebergs Arch Pharmacol 2008;377:301-13

22. Brookes KJ, Mill J, Guindalini C, et al. A common haplotype of the dopamine transporter gene associated with attention-deficit/hyperactivity disorder and interacting with maternal use of alcohol during pregnancy. Arch Gen Psychiatry 2006;63:74-81.

23. Becker K, El-Faddagh M, Schmidt MH, et al. Interaction of dopamine transporter genotype with prenatal smoke exposure on ADHD symptoms. J Pediatr 2008;152:263-9

24. Thapar A, Langley K, Fowler T, et al. Catechol 0-methyltransferase gene variant and birth weight predict early-onset antisocial behavior in children with attentiondeficit/hyperactivity disorder. Arch Gen Psychiatry 2005;62:1275-8.

25. Caspi A, Langley K, Milne B, et al. A replicated molecular genetic basis for subtyping antisocial behavior in children with attention-deficit/hyperactivity disorder. Arch Gen Psychiatry 2008;65:203-10.

26. Langley K, Heron J, O’Donovan MC, et al. Genotype link with extreme antisocial behavior: the contribution of cognitive pathways. Arch Gen Psychiatry 2010;67:1317-23.

27. Franke B, Neale BM, Faraone SV. Genome-wide association studies in ADHD. Hum Genet 2009;126:13-50.

28. Pe'er I, Yelensky R, Altshuler D, et al. Estimation of the multiple testing burden for genomewide association studies of nearly all common variants. Genet Epidemiol 2008;32:381-5.

29. Lasky-Su J, Neale BM, Franke B, et al. Genome-wide association scan of quantitative traits for attention deficit hyperactivity disorder identifies novel associations and confirms candidate gene associations. Am J Med Genet B Neuropsychiatr Genet 2008;147B:1345-54.

30. Lesch KP, Timmesfeld N, Renner TJ, et al. Molecular genetics of adult ADHD: converging evidence from genome-wide association and extended pedigree linkage studies. J Neural Transm 2008;115:1573-85.

31. Mick E, Todorov A, Smalley S, et al. Family-based genome-wide association scan of attention-deficit/hyperactivity disorder. J Am Acad Child Adolesc Psychiatry 2010;49:898-905.e3.

32. Neale BM, Lasky-Su J, Anney R, et al. Genome-wide association scan of attention deficit hyperactivity disorder. Am J Med Genet B Neuropsychiatr Genet 2008;147B:1337-44

33. Neale BM, Medland SE, Ripke S, et al. Meta-analysis of genome-wide association studies of attention-deficit/hyperactivity disorder. J Am Acad Child Adolesc Psychiatry 2010;49:884-97.

34. Bastain TM, Lewczyk CM, Sharp WS, et al. Cytogenetic abnormalities in attention-deficit/hyperactivity disorder. J Am Acad Child Adolesc Psychiatry 2002;41:806-10

35. Stephen E, Kindley AD. Should children with ADHD and normal intelligence be routinely screened for underlying cytogenetic abnormalities? Arch Dis Child 2006;91:860-1.

36. Scherer SW, Lee C, Birney E, et al. Challenges and standards in integrating surveys of structural variation. Nat Genet 2007;39:S7-15

37. Sebat J, Lakshmi B, Malhotra D, et al. Strong association of de novo copy number mutations with autism. Science 2007;316:445-9.

38. Sebat J, Levy DL, McCarthy SE. Rare structural variants in schizophrenia: one disorder, multiple mutations; one mutation, multiple disorders. Trends Genet 2009;25:528-35.

39. Elia J, Gai X, Xie HM, et al. Rare structural variants found in attention-deficit hyperactivity disorder are preferentially associated with neurodevelopmental genes. Mol Psychiatry 2010;15:637-46.

40. Lesch KP, Selch S, Renner TJ, et al. Genome-wide copy number variation analysis in attention-deficit/hyperactivity disorder: association with neuropeptide Y gene dosage in an extended pedigree. Mol Psychiatry 2011;16:491-503.

41. Williams NM, Zaharieva I, Martin A, et al. Rare chromosomal deletions and duplications in attention-deficit hyperactivity disorder: a genome-wide analysis Lancet 2010;376:1401-8.

42. Counts CA, Nigg JT, Stawicki JA, et al. Family adversity in DSM-IV ADHD combined and inattentive subtypes and associated disruptive behavior problems. J Am Acad Child Adolesc Psychiatry 2005;44:690-8.

43. Pineda D, Ardila A, Rosselli M, et al. Prevalence of attention-deficit/ hyperactivity disorder symptoms in 4- to 17-year-old children in the general population. J Abnorm Child Psychol 1999;27:455-62.

44. Keenan HT, Hall GC, Marshall SW. Early head injury and attention deficit hyperactivity disorder: retrospective cohort study. BMJ 2008;337:a1984. 
45. Academy of Medical Sciences. Identifying the environmental causes of disease: how should we decide what to believe and when to take action? London: Academy of Medical Sciences, 2007.

46. Collishaw S, Maughan B, Goodman R, et al. Time trends in adolescent mental health. J Child Psychol Psychiatry 2004;45:1350-62.

47. Rutter M, Smith D., eds. Psychosocial disorders in young people: time trends and their causes. Chichester: John Wiley \& Sons 1995.

48. Meaney MJ. Epigenetics and the biological definition of gene $\mathrm{x}$ environment interactions. Child Dev 2010;81:41-79.

49. Langley K, Rice F, van den Bree MB, et al. Maternal smoking during pregnancy as an environmental risk factor for attention deficit hyperactivity disorder behaviour. A review. Minerva Pediatr 2005;57:359-71.

50. D'Onofrio BM, Van Hulle CA, Waldman ID, et al. Smoking during pregnancy and offspring externalizing problems: an exploration of genetic and environmental confounds. Dev Psychopathol 2008;20:139-64.

51. Thapar A, Rice F, Hay D, et al. Prenatal smoking might not cause attention-deficit/ hyperactivity disorder: evidence from a novel design. Biol Psychiatry 2009;66:722-7.

52. Linnet KM, Dalsgaard S, Obel C, et al. Maternal lifestyle factors in pregnancy risk of attention deficit hyperactivity disorder and associated behaviors: review of the current evidence. Am J Psychiatry 2003;160:1028-40.

53. Mick E, Biederman J, Faraone SV, et al. Case-control study of attention-deficit hyperactivity disorder and maternal smoking, alcohol use, and drug use during pregnancy. J Am Acad Child Adolesc Psychiatry 2002;41:378-85.

54. Rice F, Harold GT, Boivin J, et al. The links between prenatal stress and offspring development and psychopathology: disentangling environmental and inherited influences. Psychol Med 2010;40:335-45.

55. Bhutta AT, Cleves MA, Casey PH, et al. Cognitive and behavioral outcomes of school-aged children who were born preterm: a meta-analysis. JAMA 2002;288:728-37.

56. Aarnoudse-Moens CS, Weisglas-Kuperus N, van Goudoever JB, et al. Metaanalysis of neurobehavioral outcomes in very preterm and/or very low birth weight children. Pediatrics 2009;124:717-28.

57. Hack M, Youngstrom EA, Cartar L, et al. Behavioral outcomes and evidence of psychopathology among very low birth weight infants at age 20 years. Pediatrics 2004;114:932-40.

58. Johnson S, Hollis C, Kochhar P, et al. Psychiatric disorders in extremely preterm children: longitudinal finding at age 11 years in the EPICure study. J Am Acad Child Adolesc Psychiatry 2010;49:453-63.e1.
59. Heinonen K, Räikkönen K, Pesonen AK, et al. Behavioural symptoms of attention deficit/hyperactivity disorder in preterm and term children born small and appropriate for gestational age: a longitudinal study. BMC Pediatr 2010;10:91.

60. Lahti J, Räikkönen K, Kajantie E, et al. Small body size at birth and behavioural symptoms of ADHD in children aged five to six years. J Child Psychol Psychiatry 2006;47:1167-74.

61. Nigg JT. ADHD, lead exposure and prevention: how much lead or how much evidence is needed? Expert Rev Neurother 2008;8:519-21.

62. Bouchard MF, Bellinger DC, Wright RO, et al. Attention-deficit/hyperactivity disorder and urinary metabolites of organophosphate pesticides. Pediatrics 2010;125:e1270-7.

63. Eskenazi B, Marks AR, Bradman A, et al. Organophosphate pesticide exposure and neurodevelopment in young Mexican-American children. Environ Health Perspect 2007;115:792-8.

64. Marks AR, Harley K, Bradman A, et al. Organophosphate pesticide exposure and attention in young Mexican-American children: the CHAMACOS study. Environ Health Perspect 2010;118:1768-74.

65. Rauh VA, Garfinkel R, Perera FP, et al. Impact of prenatal chlorpyrifos exposure on neurodevelopment in the first 3 years of life among inner-city children. Pediatrics 2006;118:e1845-59.

66. Eubig PA, Aguiar A, Schantz SL. Lead and PCBs as risk factors for attention deficit/hyperactivity disorder. Environ Health Perspect 2010;118:1654-67.

67. Sagiv SK, Thurston SW, Bellinger DC, et al. Prenatal organochlorine exposure and behaviors associated with attention deficit hyperactivity disorder in school-aged children. Am J Epidemio/ 2010;171:593-601.

68. Ballard W, Hall MN, Kaufmann L. Clinical inquiries. Do dietary interventions improve ADHD symptoms in children? J Fam Pract 2010;59:234-5.

69. Pelsser LM, Frankena K, Toorman J, et al. Effects of a restricted elimination diet on the behaviour of children with attention-deficit hyperactivity disorder (INCA study): a randomised controlled trial. Lancet 2011;377:494-503.

70. Lifford KJ, Harold GT, Thapar A. Parent-child relationships and ADHD symptoms: a longitudinal analysis. J Abnorm Child Psychol 2008;36:285-96.

71. Kreppner J, Kumsta R, Rutter M, et al. IV. Developmental course of deprivationspecific psychological patterns: early manifestations, persistence to age 15, and clinical features. Monogr Soc Res Child Dev 2010;75:79-101.
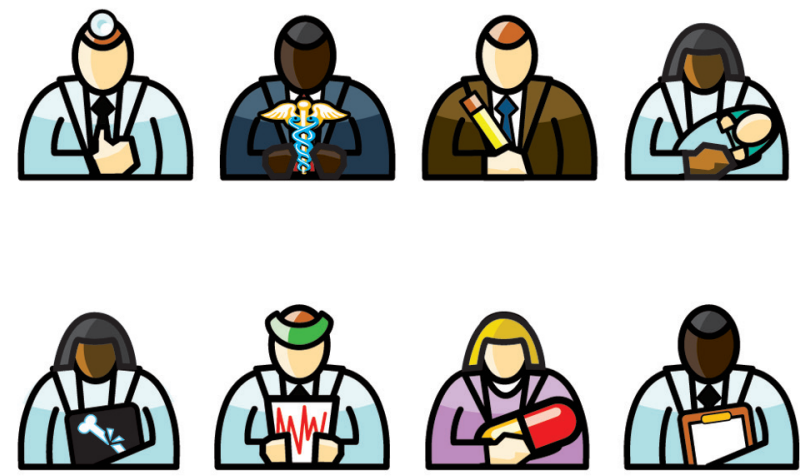

Improve your

day to day practice with BMJ Learning

In our recent user survey, 8 out of 10 respondents said they always or frequently apply what they have learnt in BMJ Learning modules to their day to day practice.

\section{Register for instant access at learning.bmj.com/register}

BMJ Learning 